\title{
Risk Evaluation of Rainstorm and Flood in the Upper Reaches of Hunhe River (Qingyuan Section) Based on the FloodArea Model
}

\author{
Mingyan Liu ${ }^{1,2}$, Fenghua Sun ${ }^{1 *}$, Yiling Hou ${ }^{2}$, Xiaoyu Zhou², Chunyu Zhao' ${ }^{2}$ Xue $\mathrm{Yi}^{2}$ \\ ${ }^{1}$ Institute of Atmospheric Environment, China Meteorological Administration, Shenyang, China \\ ${ }^{2}$ Regional Climate Center of Shenyang, Shenyang, China \\ Email: *sfh3910839@sina.com
}

How to cite this paper: Liu, M.Y., Sun, F.H., Hou, Y.L., Zhou, X.Y., Zhao, C.Y. and Yi, X. (2018) Risk Evaluation of Rainstorm and Flood in the Upper Reaches of Hunhe River (Qingyuan Section) Based on the FloodArea Model. Journal of Geoscience and Environment Protection, 6, 168-180. https://doi.org/10.4236/gep.2018.65014

Received: January 17, 2018

Accepted: May 22, 2018

Published: May 25, 2018

Copyright $\odot 2018$ by authors and Scientific Research Publishing Inc. This work is licensed under the Creative Commons Attribution International License (CC BY 4.0).

http://creativecommons.org/licenses/by/4.0/

\begin{abstract}
By using data of hourly rainfall with all of the meteorological stations in the upper reaches of Hunhe River (Qingyuan Section), the digital elevation model, the land use and the disasters data etc., the storm flood process which happened on 16 August 2013 is reproduced simulated based on the rainstorm flooding of FloodArea model, also the flooding simulation and its effectiveness have been carried out. Conclusions are drawn as follows: there is a sharp rise of the flood depth falling behind the change of rainfall three or four hours. As the accumulation of the precipitation, the water level has increased, and when the precipitation process stops, the flood pooled into midstream and downstream gradually. According to the disaster investigation, in both the aspects of flooding scope and flooding depth of warning spots, the simulation result of FloodArea model agrees with the fact. It indicates that the FloodArea model generates good simulation effect in the upper reaches of Hunhe River (Qingyuan Section). Combined with population and GDP information, in the whole river, about eighty-three thousand people were affected by flooding, also one billion and five hundred seventy five million RMB of gross domestic product was lost. When the flood depth deepens and the flooding scope increases, correspondingly the loss rate of population and GDP rises and the flood risk increases.
\end{abstract}

\section{Keywords}

The Upper Reaches of Hunhe River, FloodArea, Flood Simulation, Risk Assessment

\section{Introduction}

Rainstorms and the floods caused by them have posed a great threat to the 
transport, transportation and people's life and property of workers and peasants [1], which is the most widespread type of natural disaster affecting the most extensive and endangering human existence and development. With the intensification of global warming and the frequent occurrence of extreme weather and climate events, torrential rains and floods show the main features of seasonal features, strong intensity, long duration and wide impact range [2], which to a certain extent restrict the development of China's cities [3], the monitoring, assessment and early warning of storms and floods have become the focus of our government and scholars. The determination of flood inundation range and depth is the core of storm flood risk assessment. The hydrodynamic submergence model combined with GIS technology has been widely used in the risk assessment of storm flood. Based on GIS grid data, Su Buda et al. [4] established a two-dimensional dynamic submergence model of hydrodynamic flood, simulated the evolution process of Jingjiang flood and evaluated the submergence loss. Li Lan et al. [5] based on the analysis of historical flood risk in Zhanghe River Basin flood cases, the use of GIS-based storm flood flooding model to calculate the different periods of recurrence of surface submergence of rainfall and water depth; Xie et al. [6] used FloodArea model to simulate storm flood and flood caused by a typical heavy rainfall process in the Datong River Basin and carried out risk assessment. Wang Sheng et al. [7] carried out flood inundation simulation in the Bahe River Basin, superimposed disaster-bearing body information, and obtained risk assessment and zoning map of flood inundation period in different recurrence periods. These researches are of great significance for risk assessment and analysis of storm flood disaster. The Hunhe River is located in the central part of Liaoning Province $\left(112^{\circ} 20^{\prime}-125^{\circ} 15^{\prime} \mathrm{E}, 41^{\circ} 00^{\prime}\right.$ $42^{\circ} 15^{\prime} \mathrm{N}$ ) and belongs to the left bank of the Liao River, with a river length of $415.4 \mathrm{~km}$ and a catchment area of $11,481 \mathrm{~km}^{2}$, originating from Qingyuan County Changbai Mountains rolling Maling ridge southwest, flowing through Fushun, Shenyang and other cities and counties [8]. Hunhe is a temperate continental monsoon climate zone, affected by the southeastern monsoon, heavy rain occurred in July to August [9], a heavy rain process can last about 3 days. On August 16, 2013, heavy rainfall and floods occurred in the upper Hunhe River. Four precipitation stations in Qingyuan County exceeded the historical peak value. The peak flow and water level of the hydrological stations in the north of the mouth reached the actual measured values since the founding of New China The first one is located in the south front of the rainstorm center town, on the 16th daily precipitation as high as $449.0 \mathrm{~mm}$ [10].

In this paper, based on the field survey, in order to deal with the " 0816 " storm flood in 2013, taking the Qingyuan section of the upper Hunhe River as the research basin, FloodArea inundation model was used to simulate the process of flood inundation, and the submerged range, depth and duration were counted. The body of information, draw basin flood disaster risk map, in order to achieve the assessment of storm flood disaster scientific, systematic and quantitative 
foundation. In addition, frequent natural disasters and floods in China are the most devastating and the most deadly ones. With the rapid development of economy and society, the social impact and economic losses caused by floods are on the rise. Each year Economic losses due to floods account for more than $60 \%$ of all natural disasters. Therefore, strengthening risk management of meteorological disasters caused by floods and floods is of great significance to social and economic construction and people's lives and property.

\section{Materials and Methods}

In this paper, the rainstorm flood process occurred in Qingyuan section of Hunhe River from August 15 to August 18, 2013 as an example. The basin is located in Qingyuan Manchu Autonomous County, Fushun City, Liaoning Province, belonging to the temperate continental monsoon climate with a basin area of $2447 \mathrm{~km}^{2}$. About $151.4 \mathrm{~km}$ long, covering 9 towns and 5 townships, the total population of about 254,000 people, altitude $113-1089 \mathrm{~m}$, the terrain southeast of Northwest low, low hills and valleys staggered, the central along the Hunhe valley plain gradually slow westward, Watershed built hydrological station north exit of the former station, catchment area of $1832 \mathrm{~km}^{2}$. Hunyuan upstream $\mathrm{Hu}$ nyuan terrain, water system and meteorological site distribution shown in Figure 1.

Meteorological Information Center of Liaoning Province provided hourly precipitation data of hourly precipitation from Qingyuan Station, Beikouqian Station, Sihehezi Station and Haiyang Reservoir Station on August 15, 2013 to 08:00 August 18 at the basin. The unit is mm. By means of arithmetic mean method, the hourly anomaly series of rainfall in the basin are obtained. The

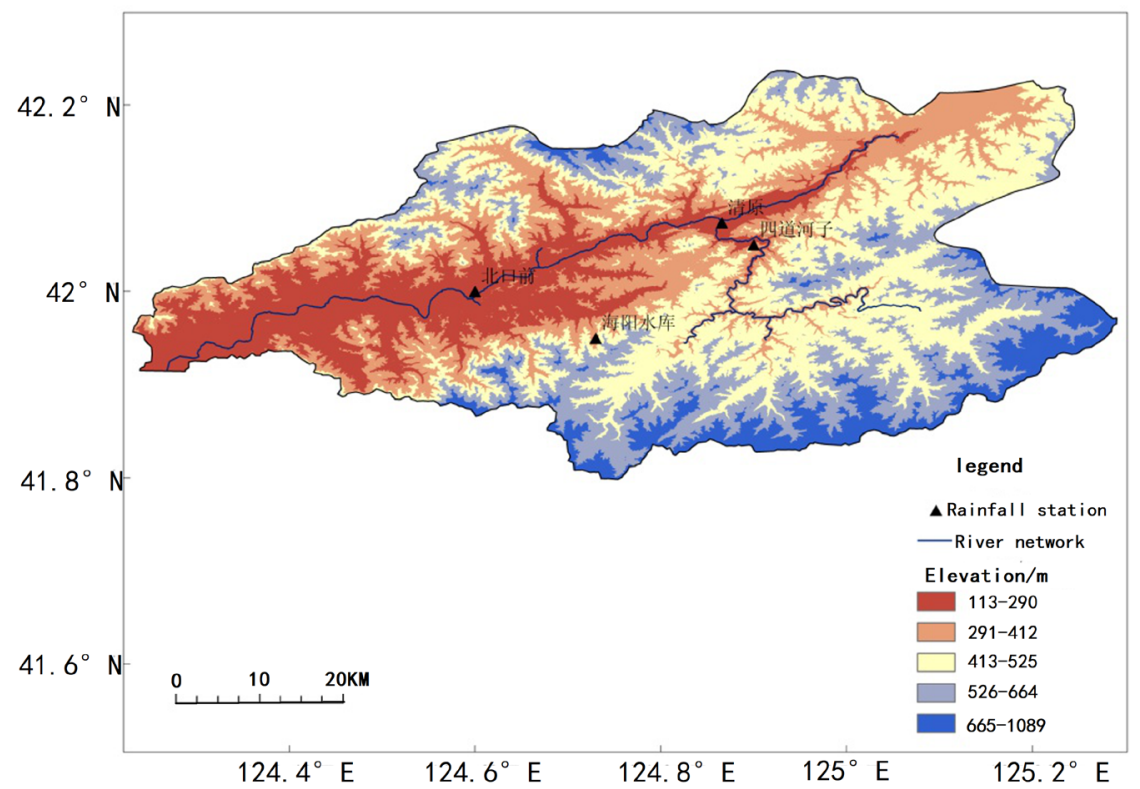

Figure 1. The terrain, water system and meteorological stations in the upper reaches of Hunhe River (Qingyuan Section). 
DEM digital elevation model is SRTM data at a resolution of $30 \mathrm{~m}$. Data on river systems and land use types from Grade 1 to 5 in Liaoning Province are from the National Climate Center. Basin population and GDP distribution data are from the population distribution data set and GDP distribution data set of China's km grid constructed by Institute of Geographic Sciences and Natural Resources Research, Chinese Academy of Sciences. Disaster information is obtained through field investigation.

Developed by Geomer AG in Germany, the FloodArea Flooding Model is based on a hydrodynamic approach [11], operates as a module in ArcGIS, and is fully integrated with the ArGIS desktop graphical user interface using spatial analysis capabilities. It simulates the evolution of floods in grid units. The Manning-Stricker formula is used to calculate the flood flow rate between each grid unit and the surrounding eight units. The submerged depth of water flow is defined as the difference between submerged water level elevation and ground elevation, and the direction of water flow Decided by the terrain aspect [12]. FloodArea operating hours, corresponding submergence ranges and water depths are stored in a grid format, which is intuitive and easy to query [13]. The simulation results can provide technical support for pre-disaster flood forecasting and flood disaster assessment. The simulation model is divided into three types, top-type, breach-type and storm-type [14].

Based on the basic geographic information, disaster investigation, hydrological data and hourly precipitation data, this paper uses the storm flood model of FloodArea submerged model to simulate the 2013 " 0816 " rainstorm flood in the Qingyuan section of upper Hun River. The simulation step is 1 hour, The model output is compared with the measured disaster data to verify the applicability of the model. The range, depth and duration of the inundation in the river basin are calculated. Based on the information of the disaster-bearing body (population and GDP), the risks that may be triggered by the flood and flood disaster are briefly described Evaluation analysis.

\section{Results and Analysis}

\subsection{Surface Rainfall}

Hourly precipitation of ground-based rainfall stations is used to calculate mean rainfall over the basin using the arithmetic mean method. Figure 2 shows the hourly-averaged rainfall series from 22:00 on August 15, 2013 to 10:00 on the 17 th, with a cumulative rainfall of $328.43 \mathrm{~mm}$. Heavy rainfall began on the early morning of the 16th and lasted until 08:00 on the 17th. Rainfall mainly concentrated on the 11th to the 22 nd on the 16 th with the maximum hourly rainfall at 17:00 on the 16th with an average rainfall of $50.95 \mathrm{~mm}$, followed by that At 20:00 on the 16th, the average hourly rainfall was $48.95 \mathrm{~mm}$.

\subsection{Model Parameters Are Determined}

Different land cover forms can intercept, store and filter the surface runoff and 
form different resistivities to flood evolution. The resistivity can be quantified to a large extent by the Manning roughness coefficient [15]. Therefore, when FloodArea flood inundation simulation analysis is carried out on the Qingyuan section of upper Hunhe River, a comprehensive parameter that can reflect the shape irregularity and roughness of the river channel or gutter wall should also be added to the model. Based on the data of land use types in the Qingyuan section of upper Hunhe River, according to the relevant literature [16], the roughness coefficients of the Qingyuan section of upper Hunhe River were determined according to the five types of residential land, water body, dry land, irrigated land and forest land, Surface type with larger roughness coefficient has larger water permeability. Table 1 shows the types of land use and their roughness. Figure 3 shows the spatial distribution of surface water stress Strilker coefficients obtained through land use types conversion. As can be seen from the figure, most of the watershed is covered by forest land, residential areas, dry land and

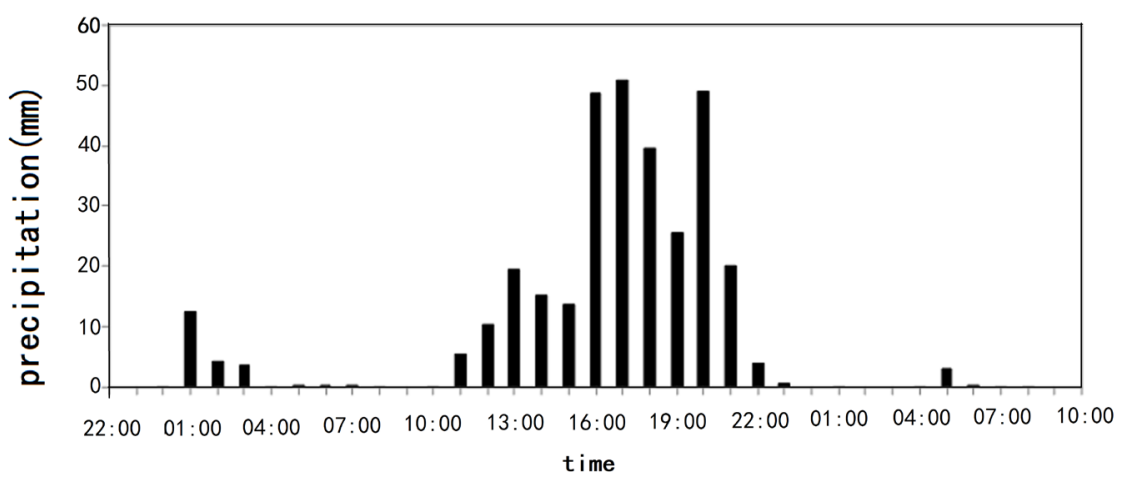

Figure 2. Hourly surface precipitation sequence in the upper reaches of Hunhe River (Qingyuan Section).

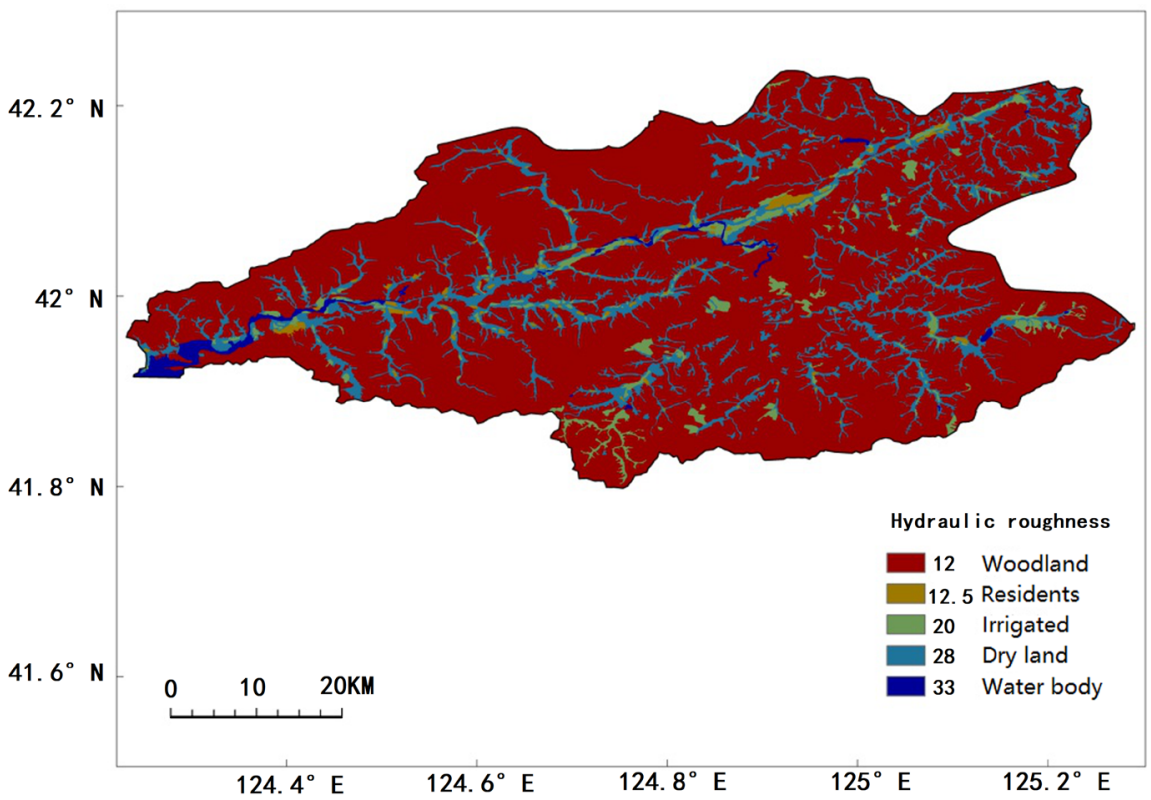

Figure 3. Water roughness value of surface hydraulic power. 
Table 1. Land utilization types and roughness coefficient.

\begin{tabular}{cccccc}
\hline $\begin{array}{c}\text { Land cover } \\
\text { classification }\end{array}$ & Residents & Water body & dry land & Irrigated & woodland \\
\hline Strilker coefficient & 12.5 & 33.0 & 28.0 & 20.0 & 12.0 \\
\hline
\end{tabular}

water Irrigation is located in the banks of the river, paddy fields sporadically distributed in the middle and lower reaches.

The SCS (Soil Conservation Service) model developed by USDA Soil and Water Conservation Bureau was used to determine the surface runoff coefficient. The model can reflect the influence of underlying surface conditions on the confluence process. This method is chosen because of its simple structure, less parameters and easier access to data, which can reflect the effects of soil types, land use patterns and the previous soil moisture content on rainfall runoff, and can effectively calculate the runoff of catchments in the Qingyuan section of Hunhe upstream [17]. The model is calculated as:

$$
\begin{gathered}
S=25400 / C N-254 \\
Q=(P-0.2 S)^{2} /(P+0.8 S) \\
K=Q / P
\end{gathered}
$$

where, $Q$ is the output flow, $P$ is the precipitation, $S$ is the potential infiltration, $\mathrm{K}$ is the dimensionless coefficient of flow coefficient. Curve Number $(C N)$ reflects the characteristics of the watershed before rainfall. It varies with the state of soil moisture, slope, land cover, land use status and soil type in the early stage of the river basin, and can be found according to Chapter 4 of the National Engineering Handbook $C N$ values corresponding to land use patterns and soil textures [18]. Larger $C N$ values are more prone to runoff (See Figure 4).

\subsection{Flood and Flood Inundation Simulation}

According to the DEM data, the surface runoff coefficient, the surface water-surface roughness and the hour-by-hour rainfall series corresponding to the rainstorm flood process in the Qingyuan section of upper Hunhe River, FloodArea submerged model rainstorm model was used in the GIS environment, The scenario of rainstorm and flood in 2013 " 0816 " of Qingyuan section of Hunhe River was simulated. The simulation time was 57 hours from 0:00 on August 16, 2013 to $08: 00$ on the 18th and the exchange rate was set at 5\%. Through the model output and field investigation of flood inundation depth and duration of the data, comparative analysis verify the applicability of the model.

Selected Qinghai County, Fushun City, south of the former village and Haiyang village hidden points for the watershed, for the storm flood process, the location of the hidden spots, altitude and flood inundation process were investigated (Table 2), the hidden spots in the muddy In the upper reaches of the river, the population is concentrated, the agriculture is developed, the property is rich, there are many factories in the village, and the economic benefits are good. 


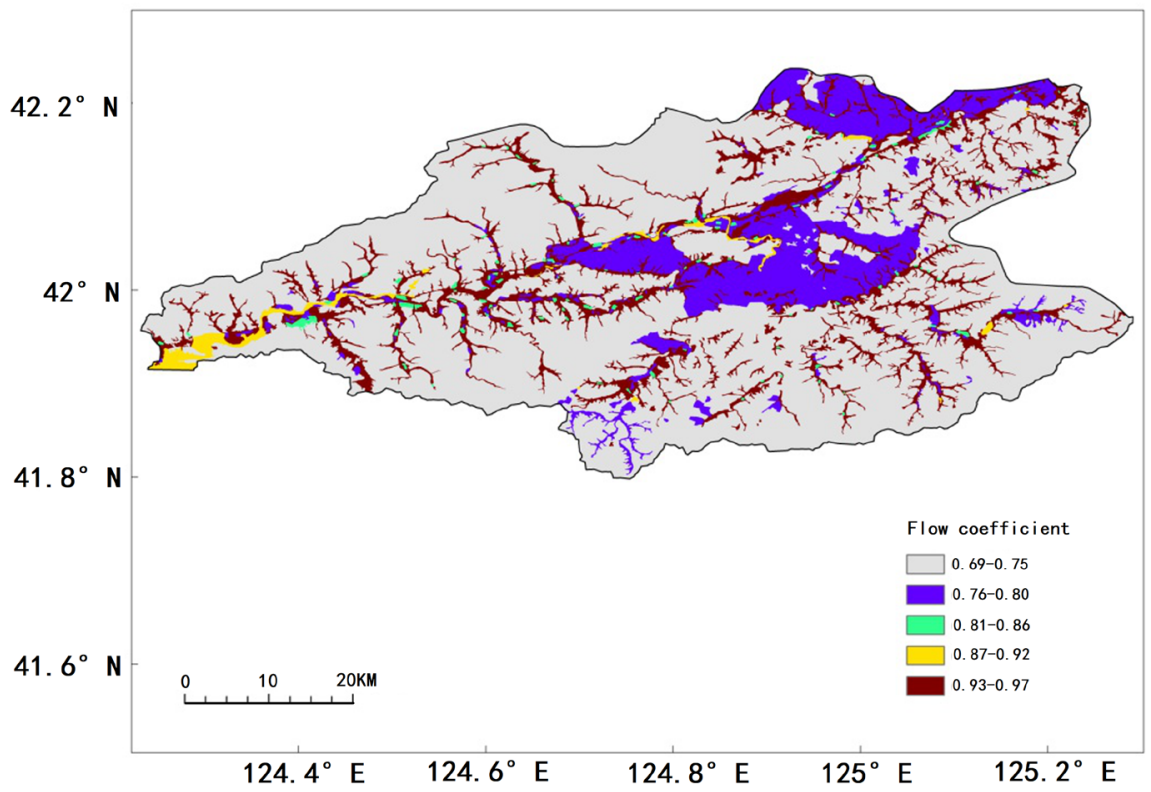

Figure 4. Runoff coefficient value.

Table 2. Form of investigation in the upper reaches of Hunhe River (Qingyuan Section).

\begin{tabular}{cccccc}
\hline Hidden point & longitude & latitude & Altitude/m & $\begin{array}{c}\text { Maximum } \\
\text { submergence } \\
\text { depth/m }\end{array}$ & $\begin{array}{c}\text { Submerged peak } \\
\text { appearance time }\end{array}$ \\
\hline $\begin{array}{c}\text { South front of the } \\
\text { village }\end{array}$ & $124^{\circ} 36^{\prime} 14^{\prime \prime}$ & $41^{\circ} 58^{\prime} 58^{\prime \prime}$ & 149.5 & 3.0 & 16 th, $18-23$ \\
\begin{tabular}{l} 
Haiyang village \\
\hline
\end{tabular} & $124^{\circ} 41^{\prime} 51^{\prime \prime}$ & $41^{\circ} 59^{\prime} 10^{\prime \prime}$ & 218.7 & 2.83 & \\
\hline
\end{tabular}

When there is flood in the drainage basin, the hidden danger point in the upstream of Hun River is the place where the flood arrives earlier.

The submerged simulation shows that the maximum inundation occurred at 17 o'clock on the 16th at Nankoukou village, and the submerged depth reached $2.3 \mathrm{~m}$. At Haiyang village at 21:00 on the 16th, the submerged maximum appeared and the submerged depth reached $3.4 \mathrm{~m}$. The submerged depth of hidden danger points gradually deepened with the accumulation of precipitation. As the process of precipitation stopped, the submergence depth decreased slowly at 06:00 on the 17th. The maximum submerged depth and the maximum submerged depth of the simulated hidden danger spots were compared with those on the ground The results are basically similar (Figure 5), indicating that the FloodArea model has good flood inundation simulation results in the upper reaches of Hunhe River, which can be used for risk management and early warning of rainstorm, flood and flood in this basin.

As for the whole basin (Figure 6), after the precipitation occurred at 01:00 on the 16th, submergence occurred in the Qingyuan section of the upper Hun River. However, due to the short period of precipitation and less precipitation, the evolution of flood was slower and the depth of submergence was basically increased 
due to the surface runoff, the submerged area is smaller and the submerged depth is less than $0.5 \mathrm{~m}$. At 11 o'clock on the 16th, the rainfall began to increase. With the increase of precipitation and time, the water level rose rapidly and the depth of inundation deepened. The flooding continued to spread, and the submerged depth of more than $0.5 \mathrm{~m}$ gradually increased and submerged Submerged areas with water depths of $0-0.5 \mathrm{~m}, 0.5-1.0 \mathrm{~m}, 1.0-2.0 \mathrm{~m}$ and $2.0 \mathrm{~m}$ were $113.2 \mathrm{~km}^{2}$, $10.1 \mathrm{~km}^{2}, 14.5 \mathrm{~km}^{2}$ and $6.1 \mathrm{~km}^{2}$, respectively. At 18:00 on the 16th or so, the hourly precipitation reached the maximum. Due to the continuous influence of the precipitation process, the inundation of the river basin continued to deepen. The river water level rose significantly. The flood spread throughout the river basin and accelerated to the downstream. The submerged depth exceeded $0.5 \mathrm{~m}$, about $41.3 \%$ of the area. At 0800 UTC on the 17 th, the precipitation process basically ended, and the flood on both sides of the river receded gradually. Influenced by the terrain, the upstream flood flow went downstream along the river, the submerged depth gradually decreased and the downstream submerged depth increased. After which the water depth slowly decreased. In general, the depth of submergence of the Qingyuan segment of the upper Hunghuidian section of the Hun River gradually deepened with the increase of precipitation, especially the flood accumulation in the lower reaches of the Hun River. After the precipitation stopped, the flood flow went down the river channel, and the submerged depth of the upstream dropped significantly. Slowly declining trend. Taking into account the basin area, infiltration of rainwater and confluence and other actual conditions, the basin flooded lag about 3 - $4 \mathrm{~h}$ response to changes in precipitation.

\subsection{Flood Inundation Impact Assessment}

After the text edit has been completed, the paper is ready for the template. Duplicate the template file by using the Save As command, and use the naming convention prescribed by your journal for the name of your paper. In this newly created file, highlight all of the contents and import your prepared text file. You are now ready to style your paper.

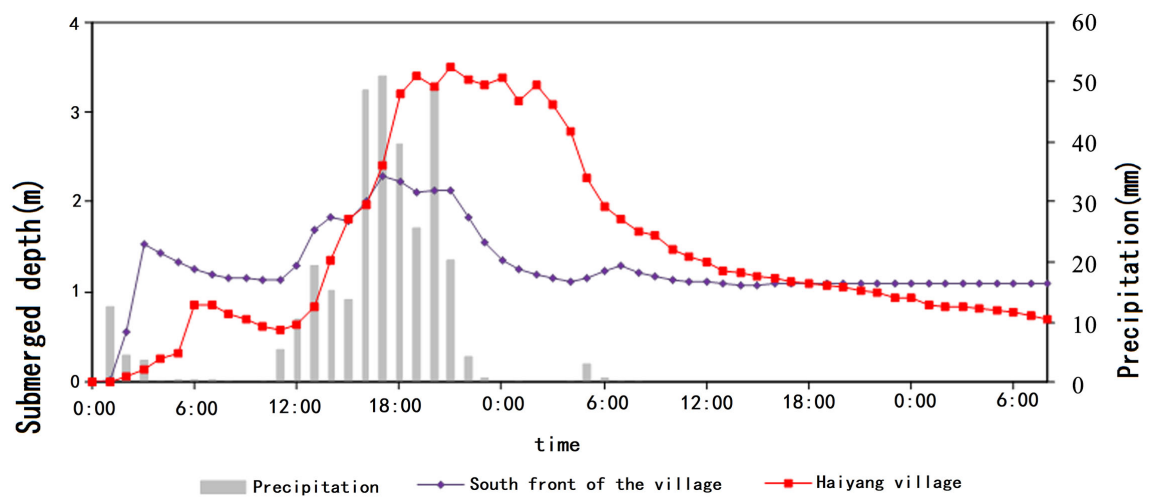

Figure 5. Flood depth in warning spots. 


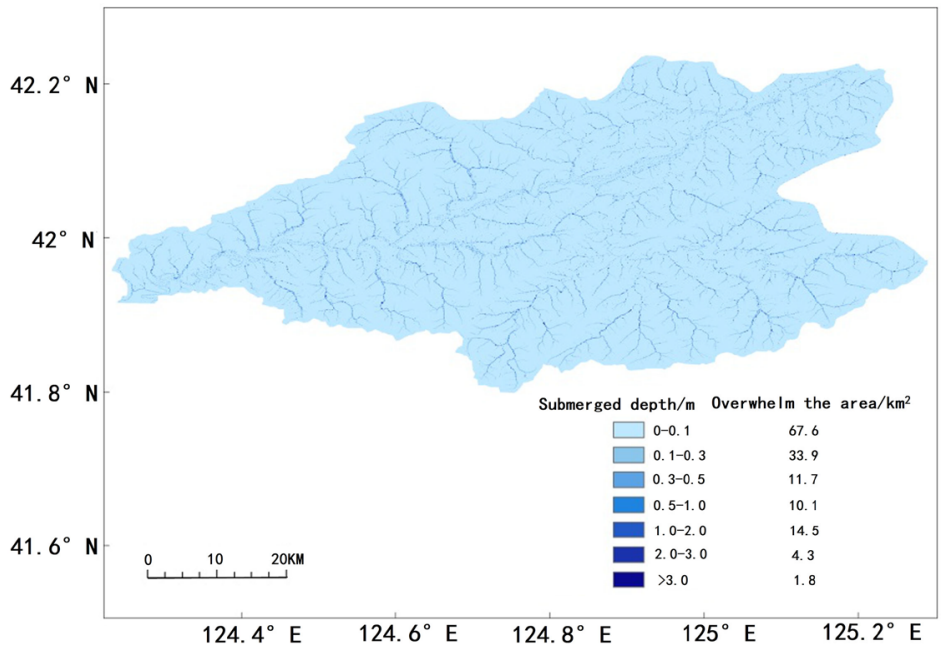

(a)

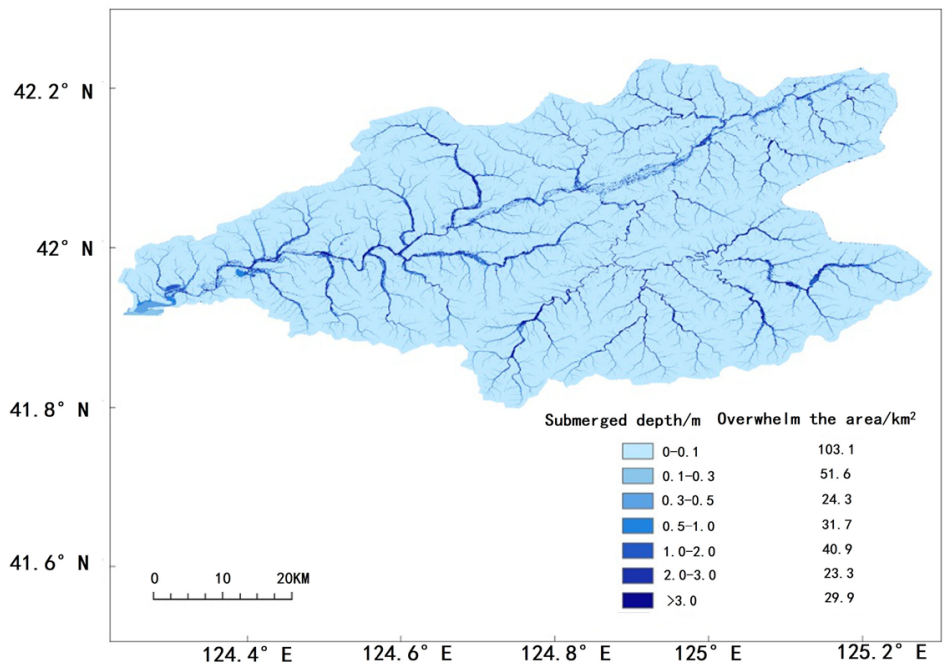

(b)

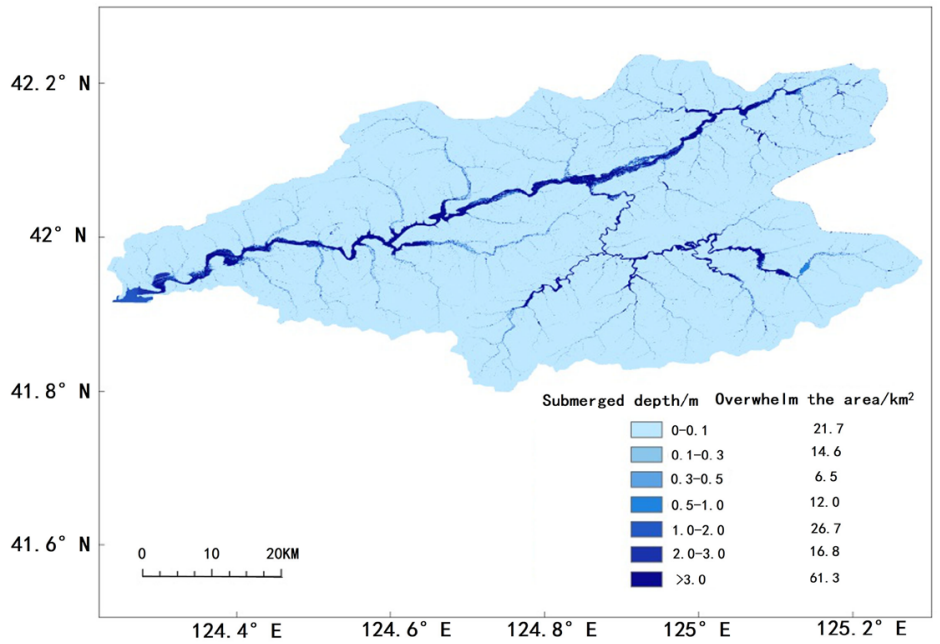

(c)

Figure 6. Simulation of the flood at 13:00 on Aug 16 (a) 18:00 on Aug 16; (b) and 08:00 on Aug 17; (c) in the upper reaches of Hunhe River (Qingyuan Section). 
Based on the simulation of FloodArea submerged model, the submerged depth and submerged depth of Qingyuan section of upper Hunhe during the storm flood were obtained. Based on this, the information of disaster-bearing body (population and GDP) in submerged watershed was superimposed and evaluated the extent of disaster-affected bodies affected by flood under different submergence depths. According to the submerged depth $(<0.5 \mathrm{~m}, 0.5-1.0 \mathrm{~m}, 1.0$ $-2.0 \mathrm{~m},>2.0 \mathrm{~m}$ ), the potential risks of disaster-bearing bodies are respectively divided into four levels of low risk, medium risk, high risk and high risk [19] [20]. Statistics show that the population and GDP are affected by different levels of risk during the entire submergence.

According to the statistics of the 2010 CAS Institute of Geography, there are about 254,000 Qingyuan sections of the upper Hun River, with a total GDP of 6.13 billion yuan. Figure 7 shows the disaster-bearing body disaster damage rate curve affected by the flooding at 11 o'clock on the on the 16th of 2013 and at 0800 on the 18th. At 01:00 on August 16, the Qingyuan section of the upper Hun River gradually submerged with the onset of precipitation, and the precipitation became more concentrated at 11 a.m. on the 16th. With the increase of the rainfall, the flood inundation area gradually increased and the flooding affected The population and GDP also increased rapidly, and the disaster loss rate of disaster-bearing bodies increased significantly. At 21:00 on the 16th, the maximum inundation range of the watershed was reached, and the population and GDP affected by flood inundation reached the maximum correspondingly. Afterwards, flood inundation scope gradually decreased and corresponding disaster-bearing body disaster loss rate also decreased but the rate of decline was very slow. Table 3 shows the average population and GDP under different levels of inundation during the flood period. Most of the submerged areas are below $0.5 \mathrm{~m}$ from the beginning of submergence to the end of submergence, so the population at low risk of loss with a large number of GDP, in which the affected population of about 30,200 people, GDP amounted to 453,000,000 yuan. With the accumulation of precipitation and the flood spread, the submerged depth of more than $0.5 \mathrm{~m}$ range gradually increased. On average, as the depth of submergence increased, the degree of plagues affected by the plagues continued to increase and the risk of floods also increased. Affected by the torrential rains and torrential rains, about 83,000 people were affected in the Qingyuan segment upstream the Hunhe River, with economic losses of up to Up to 1.575 billion yuan.

Table 3. Population and GDP under different simulated flood depth.

\begin{tabular}{ccc}
\hline Different risk levels & Population (million) & GDP (100 million yuan $)$ \\
\hline low risk & 3.02 & 4.53 \\
Medium risk & 0.53 & 1.19 \\
high risk & 1.91 & 2.88 \\
Very high risk & 2.82 & 7.15 \\
\hline
\end{tabular}




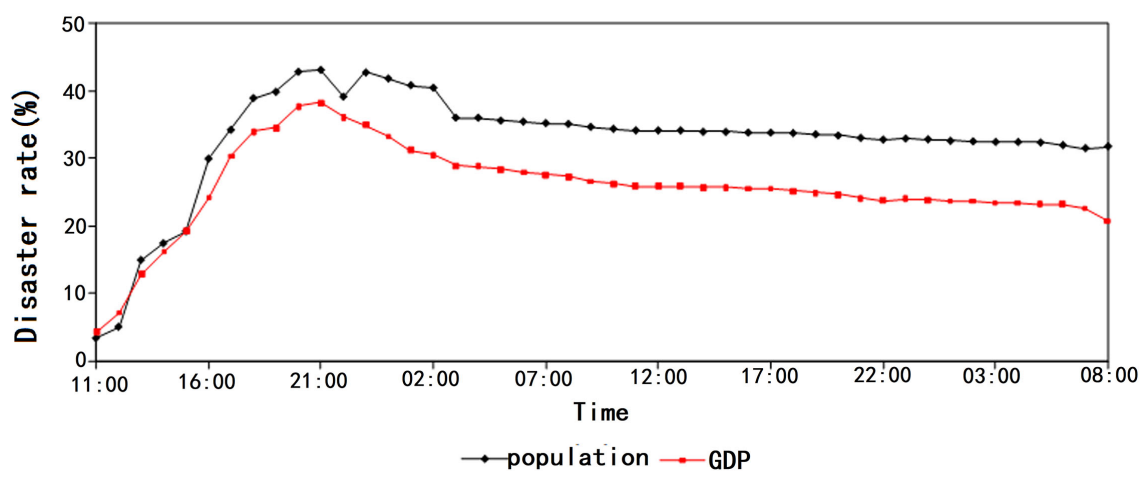

Figure 7. Loss rate of population and GDP.

\section{Conclusion and Discussion}

Based on the field survey, aiming at the flood and flood in "0816" in 2013, taking the Qingyuan section of Hunhe River as the research area, the FloodArea submerged model was used to simulate the flood and flood disaster based on the data of meteorological, hydrological and geographical information in the basin. When flood occurred, the depth, range and duration of flood inundation, combined with the precipitation histogram to draw the warning submerged depth curve, the simulation results and the measured values were compared. The simulated submerged depth and range are consistent with the field survey. The model has good simulation results in the Qingyuan section of the upper Hunhe River. Based on this, the submerged range and depth space map of the drainage area are drawn, and combined with the information of the disaster-bearing body, a brief assessment of the risks posed by the storm floods, the conclusion is as follows.

1) The submergence of the basin lags behind that of the precipitation by about $3-4 \mathrm{~h}$, and the submergence depth will deepen with the increase of precipitation after the precipitation. After the precipitation stops, the flood flows down the river, the depth of the upstream submergence decreases significantly, and the submerged depth of the middle and lower reaches is slow decline in the trend.

2) Combined with the information of disaster-bearing bodies in the basin, GIS is used to evaluate the socio-economic impacts of this rainstorm and flood process on the Qingyuan section of upper Hunhe River. On average, when the flooding depth deepens and the scope increases, the corresponding disaster-bearing body disaster damage rate is higher, and the risk of storm floods is relatively increased. Affected by the storm flood, a total of about 83,000 people were affected and the economic loss reached 1.575 billion yuan.

3) In this study, a heavy rainfall model of FloodArea submerged model was used to invert a typical flood process in Qingyuan section of upper Hunhe River. The hourly precipitation used in the simulation was the averaged surface rainfall sequence, and the mean precipitation value was lower than that of single station. The actual rainfall, the simulation results may be deviated from the actual situation. In addition, taking into account the diversity of flood inundation scenarios, 
other models of FloodArea model can be used to simulate the watershed and compared with the simulation results to improve the application of the model in Hunhe River Basin.

\section{Acknowledgements}

This work was jointly funded by China Meteorological Administration Climate Change Special Project (CCSF201608); Liaoning Province Science and Technology Program (2015103038); China Meteorological Administration Climate Change Special Project (CCSF201609); Liaoning Meteorological Bureau Scientific Research Project (201503); China Meteorological Administration Shenyang Atmospheric Environment Research Open Fund Project Funding.

\section{References}

[1] Jing, Z., Gu, H., Zheng, L., et al. (2014) Encyclopedia of Rivers and Lakes in China section of Heilongjiang River and Liaohe River. China Water Power Press, Beijing, 268-271.

[2] Shi, P.J. (1995) The Natural Disasters, Constructions Works for Disaster Reduction and Sustainable Development of China. Journal of Natural Resources, 10, 267-278.

[3] Hu, H.B., Xuan, C.Y. and Zhu, L.S. (2013) The Pre-Event Risk Assessment of Beijing Urban Flood. Journal of Applied Meteorological Science, 24, 99-108.

[4] Su, B.D., Jiang, T., Guo, Y.Y., et al. (2005) GIS Raster Data-Based Dynamic Flood Risk Simulation Model and Its Application. Journal of Hohai University (Natural Sciences), 33, 370-374.

[5] Li, L., Zhou, Y.H., Ye, L.M., et al. (2013) Basin Rainstorm Flood Risk Regionalization Method Based on GIS Rainstorm Flood Inundation Model. Meteorological Monthly, 39, 112-117.

[6] Xie, W.S., Tian, H. and Lu, Y.Y. (2015) Risk Evaluation of Rainstorm and Flood Disasters in Datong River Basin Based on the FloodArea Model. Torrential Rain and Disasters, 34, 384-387.

[7] Wang, S., Wu, R., Xie, W.S., et al. (2016) Rainstorm Induced Mountain Flood Disaster Risk Zoning Based on FloodArea Inundation Model-Taking Pihe River Vally as a Case. Climate Change Research, 12, 432-441.

[8] Lan, H., Yang, L., Qiu, J.W., et al. (1997) Numerical Simulation for Flood Control Standard of Southern Embankment of Hunhe River in Shenyang City. Journal of Natural Disasters, 6, 95-101.

[9] Liu, W., He, J.S. and Chen, Y. (2016) Variation Characteristics and Synchronicity Analysis of the Precipitation and Runoff in Hunhe River Basin. Research of Soil and Water Conservation, 23, 150-154.

[10] Liu, M.Y., Wang, Y., Zheng, S., et al. (2015) Critical Precipitation Determination for a “0816” Torrent Event in Qingyuan, Liaoning Province. Journal of Meteorology and Environment, 31, 25-30.

[11] Ji, X.J., Li, F.X., Zhu, Y.Y., et al. (2015) Determination of Area Rainfall Threshold of Flash Flood in the Upper Reaches of Luohe River of He'nan Province. Journal of Meteorology and Environment, 31, 43-50.

[12] Wen, M.Z., Lin, X., You, L.J., et al. (2013) Risk Rainfall Assessment Methods of Flash Floods Disaster. Meteorological Monthly, 39, 1325-1330. 
[13] Zhang, L., Wang, W., Wen, M.Z., et al. (2015) Research on Refined Early-Warning Method of Mountain Flood Disaster Based on FloodArea. Journal of Fudan University (Natural Science), 54, 282-287.

[14] Dai, Y.H., Huang, L.T., Li, M.Z., et al. (2016) Simulation Study of Flood in Longxu River Basin Based on the FloodArea Model. Journal of Meteorological Research and Application, 37, 46-50.

[15] Zhang, H.J. and Hikaru, K. (1995) A Study on Effect of Forest Land Condition upon Roughness Coefficient in the Waet of Shanxi Province. Bulletin of Soil and Water Conservation, 15, 10-21.

[16] Zhang, H.J., Hikaru, K., Xie, M.S., et al. (1994) Study on Roughness Coefficient under the Conditions of Several Land Utilization in the West of Shanxi Province. Journal of Beijing Forestry University, 16, 86-91.

[17] Liu, J.F., Jiang, W.G., Zhan, W.F., et al. (2010) Processes of SCS Model for Hydrological Simulation: A Review. Research of Soil and Water Conservation, 17, 120-124.

[18] Peng, D.Z. and You, J.J. (2006) Application of Modified SCS Model into Runoff Simulation. Journal of Water Resources and Water Engineering, 17, 20-24.

[19] Shi, R.Q., Liu, N., Li, L., et al. (2013) Application of Rainstorm and Flood Inundation Model in Flood Disaster Economic Loss Evaluation. Torrential Rain and Disasters, 32, 379-384.

[20] Liu, W.K. and Zhang, H. (2012) The Assessment of Economic Risk Submerged in Harbin City Based on GIS RS. Journal of Northeast Agricultural University (Social Science Edition), 10, 68-72. 